\title{
BALLOON BORNE IN-SITU DETECTION OF OH IN THE STRATOSPHERE FROM 37 TO 23 KM
}

\author{
R. M. Stimpfle, L. B. Lapson, P. O. Wennberg and J. G. Anderson \\ Department of Earth and Planetary Sciences and Department of Chemistry \\ Harvard University, Cambridge, MA
}

\begin{abstract}
The $\mathrm{OH}$ number density in the stratosphere has been measured over the altitude interval of 37 to 23 $\mathrm{km}$ at midday via a balloon-borne gondola launched from Palestine, Texas on July 6, 1988. OH radicals are detected with a laser induced fluorescence instrument employing a $17 \mathrm{kHz}$ repetition rate copper vapor laser pumped dye laser optically coupled to an enclosed flow, in-situ sampling chamber. $\mathrm{OH}$ abundances ranged from $88 \pm 31 \mathrm{pptv}$ $\left(1.1 \pm 0.4 \times 10^{7}\right.$ molec $\left.\mathrm{cm}^{-3}\right)$ in the 36 to $35 \mathrm{~km}$ interval to $0.9 \pm 0.8 \mathrm{pptv}\left(8.7 \pm 7.7 \times 10^{5}\right.$ molec $\left.\mathrm{cm}^{-3}\right)$ in the 24 to $23 \mathrm{~km}$ interval. The stated uncertainty $( \pm 1 \sigma)$ includes that from both measurement precision and accuracy. Simultaneous detection of ozone and water vapor densities was carried out with separate on-board instruments.
\end{abstract}

\section{Introduction}

In this paper we present midday, in-situ measurements of the $\mathrm{OH}$ radical number density in the stratosphere obtained via a balloon-borne gondola launched from Palestine, TX on July 6,1988 . OH is detected using the laser induced fluorescence technique in combination with an enclosed-flow sampling method. These $\mathrm{OH}$ measurements follow results obtained by this instrument on July 15, 1987 as described in earlier manuscript [Stimpfle and Anderson, 1988], here after referred to as SA. The gondola was configured identically in both flights with separately controlled instruments designed to detect $\mathrm{O}_{3}$ [Weinstock et al., 1986) and $\mathrm{H}_{2} \mathrm{O}$ vapor (Schwab et al., J. Geophys. Res., to be submitted), providing simultaneous measurements of these two species in addition to the $\mathrm{OH}$ measurements.

The need for simultaneous measurements of closely coupled molecular species in the atmosphere in order to obtain a more insightful and cohesive data base is wellestablished. This is especially true with the hydroxyl radical since it is a short-lived radical that is in photochemically controlled steady state with other species that have widely varying characteristic lifetimes. For example, $\mathrm{O}_{3}$ and $\mathrm{H}_{2} \mathrm{O}$, are long-lived, transport controlled species. $\mathrm{NO}, \mathrm{O}$, and $\mathrm{HO}_{2}$ are short-lived, photochemically controlled species. $\mathrm{H}_{2} \mathrm{O}_{2}, \mathrm{HNO}_{3}$ and $\mathrm{HNO}_{4}$ are both transport and photochemically controlled species thus complicating the interpretation of individual measurements. Accompanying number density measurements of as many kinetically coupled species as possible is a critical improvement in the ability of in-situ measurements to assess the validity of model calculations of stratospheric photochemistry.

In this paper we present $\mathrm{OH}$ results alone.

\section{Experimental}

The experimental method is summarized in SA. Here we briefly restate the operating principal. $O H$ is detected by laser induced fluorescence, whereby $\mathrm{OH}$ is pumped

Copyright 1989 by the American Geophysical Union.

Paper number 89GL03359.

0094-8276/89/89GL-03359\$03.00 with a pulsed, $17 \mathrm{kHz}$ repetition rate laser in the $A-\mathrm{X}$ $(1,0)$ band around $282 \mathrm{~nm}$ and $\mathrm{OH}$ fluorescence is observed in the $(0,0)$ band around $309 \mathrm{~nm}$ with a $4.1 \mathrm{~nm}$ FWHM detector. The reported data are collected during balloon descent as ambient stratospheric air is drawn through a cyclindrical $12.5 \mathrm{~cm}$ i.d. detection chamber housing the optical components that define the detection volume.

The observed detector count rate at $309 \mathrm{~nm}$ includes various background sources in addition to $\mathrm{OH}$ fluorescence. An $\mathrm{OH}$ number density measurement requires tuning the laser wavelength on and off resonance with a selected $\mathrm{OH}$ absorption line to provide a measure of this background signal. The difference in the resonant, $\mathrm{S}^{O_{n}}$, and non-resonant, $\mathrm{S}^{\mathcal{O} f}$, signals yields the signal due to $\mathrm{OH}$ fluorescence:

$$
\begin{aligned}
& S^{\text {On }}=S^{\mathrm{OH}}+S^{\mathrm{Solar}}+S^{\mathrm{Chb}}+S^{\mathrm{Bdg}} \\
& S^{\mathrm{Off}}=S^{\mathrm{Solar}}+S^{\mathrm{Chb}}+S^{\mathrm{Bdg}} \\
& S^{\mathrm{OH}}=S^{\mathrm{On}}-S^{\mathrm{Off}}
\end{aligned}
$$

where $S^{\text {Solar }}$ is the contribution from Rayleigh scattered sunlight off the atmosphere visible below the instrument and in the detector band width. $S^{\text {Chb }}$ is the contribution from chamber scattered laser light. $S^{\mathrm{Bdg}}$ is the laser induced background signal and is composed mainly of Raman scattered and Rayleigh scattered laser light that leaks through the $309 \mathrm{~nm}$ detection channel. A single tuning cycle takes place in a 20 sec period composed of $10 \mathrm{sec}$ of resonant data integration, followed by $10 \mathrm{sec}$ of non-resonant data integration.

The $309 \mathrm{~nm}$ detector count rate is fed into two separate pulse counters. Both are gated, one with a fixed 530 nsec gate, the other with an adjustable gate, which was varied from 380 to $160 \mathrm{nsec}$ during the flight. The adjustable gate detector width is decreased during the flight in order to decrease the background solar signal which is the largest component of the non-resonant background signal. The count rate occurring outside the gate, i.e., the remaining $59 \mu \mathrm{sec}$ of intervening time between laser pulses, is stored in a separate channel and used as a measure of the solar background source strength. This counter architecture allows partitioning the observed count rate into its components as described in SA.

The task of optimizing the laser overlap integral with an identified $\mathrm{OH}$ absorption line is accomplished with two partially redundant optical devices. The first is an $\mathrm{OH}$ reference cell that uses a Xe lamp to photolyze a trace amount of water vapor in $\sim 600$ torr of Ar to form a steady state $\mathrm{OH}$ density. The laser beam passes through the reference cell, pumps ground state $\mathrm{OH}$, and produces $\mathrm{OH}$ fluorescence observable with a PMT orthogonal to the beam. The second device is a scanning spectrometer that overlays a beamsplit fraction of the laser output on to the A-X $(1,0)$ emission spectrum from an of powered $O H$ resonance lamp. The resulting spectra provide unambigunus identification of the laser wavelength.

\section{Calibration}

The instrument sensitivity to $\mathrm{OH}$ is calibrated in a laboratory prior to flight by inserting the core of the detec- 
tion module into a flow tube. Known $\mathrm{OH}$ densities are produced in the flow tube by titrating $\mathrm{NO}_{2}$ with excess $\mathrm{H}$ atom concentrations, using the $\mathrm{H}+\mathrm{NO}_{2} \rightarrow \mathrm{OH}+\mathrm{NO}$ reaction. The observed count rate due to $\mathrm{OH}, S^{\mathrm{OH}}$ in counts $\sec ^{-1}$, is given by the following expression:

$$
S^{\mathrm{OH}}=C^{\mathrm{OH}} E Q[\mathrm{OH}]
$$

where $C^{\mathrm{OH}}$ is the calibration constant determined by direct measurement, $E$ is the laser power in $\mathrm{mW}, Q$ is the fluorescence efficiency (unitless), and $[\mathrm{OH}]$ is the density in molec $\mathrm{cm}^{-3}$.

The calibration experiments were performed at room temperature in 4 to 4.2 torr of $\mathrm{N}_{2}$ carrier gas. Although a simulated air mixture would more closely match the quenching environment in ambient conditions, it cannot be used because $\mathrm{O}_{2}$ would rapidly react with $\mathrm{H}$ atoms to form $\mathrm{HO}_{2}$, complicating the simple $\mathrm{NO}_{2}$ titration scheme. The following ranges in $[\mathrm{OH}]$ and $E$ were used, $1 \times 10^{8} \leq$ $[\mathrm{OH}] \leq 1 \times 10^{9}$ molec $\mathrm{cm}^{-3}$ and $1.3 \leq E \leq 2.1 \mathrm{~mW}$. The resulting value for $C^{\mathrm{OH}}$,

$$
C^{\mathrm{OH}}=1.2 \pm .30 \times 10^{-5}\left(\frac{\text { counts } / \mathrm{sec}}{\mathrm{mW} \cdot Q \cdot[\mathrm{OH}]}\right)
$$

is in good agreement with our expectations based on the calibration for the 1987 flight.

Extraction of $\mathrm{OH}$ densities from the measured fluorescence signal requires calculation of the fluorescence efficiency, $Q . Q$ is calculated from averaged values of published $O H$ quenching and lifetime data as described in SA. In addition to the references cited in $\mathrm{SA}$ two more recent studies are included, [Burris et al., 1988] and [Copeland et al., 1988]. These studies focus on energy transfer out of the $A^{2} \Sigma^{+}, V=1$ state and both indicate somewhat faster vibrational relaxation, $V=1$ to $V=0$, in the $A^{2} \Sigma^{+}$state. The appropriate value for $\mathrm{N}_{2}$ is now more likely $2.2 \times$ $10^{-10}\left(\mathrm{~cm}^{3} \mathrm{molec}^{-1} \mathrm{sec}^{-1}\right)$ instead of $1.6 \times 10^{-10}$, the value for $\mathrm{O}_{2}$ is $3.5 \times 10^{-11}$ instead of $1.4 \times 10^{-11}$. The value of $Q$ is not exceedingly sensitive to these adopted average rate constant changes. $Q$ increases by only $10 \%$ due to the $\mathrm{N}_{2}$ rate increase since the ratio of the $V$-to- $V$ rate to the total $\mathrm{V}=1$ relaxation rate is dominated by the $\mathrm{N}_{2} \mathrm{~V}$-to-V rate. The $\mathrm{O}_{2} \mathrm{~V}$-to- $\mathrm{V}$ rate increase leads to an insignificant $1 \%$ increase in $Q$ since the $\mathrm{O}_{2}$ contribution continues to be dominated by the $\mathrm{N}_{2}$ contribution.

Our $\mathrm{OH}$ measurements are easily corrected for refinements in the value of $Q$. Since the calibration normalizes our measurements to a well-defined quenching environment in the lab (4.1 torr of $\mathrm{N}_{2}$ at room temperature) our results are relatively insensitive to large changes in $Q$. The net effect of adopting the new rates above is a $5 \%$ decrease in the $\mathrm{OH}$ number densities reported in SA. The data base for collisional energy transfer reactions of excited $\mathrm{A}^{2} \Sigma^{+} \mathrm{OH}$ has steadily improved in number and quality over the last ten years and it is unlikely that large changes in $Q$ loom in the future due to errors in the rate measurements. The new $\mathrm{V}-\mathrm{V}$ rates given above are adopted in the analysis of the present results. The remaining rate constants we use to calculate $Q$ are as reported in SA.

\section{Results}

The gondola was launched at 715 CDT on July 6, 1988 from the National Scientific Balloon Facility (NSBF) in Palestine, Texas. A peak altitude of $37.0 \mathrm{~km}$ was reached at $1000 \mathrm{CDT}$. The gondola remained at this peak altitude, for one hour and twenty minutes in order to satisfy NSBF safety requirements concerning projected downrange landing sites. During this time the $O H$ instrument was brought to a fully operational status in preparation for descent. Descent began at 1120 CDT as two stubducts were opened to release helium. A peak descent rate of $12 \mathrm{~m} \mathrm{sec}^{-1}$ was reached at 1123 CDT. However NSBF personnel regulated the average descent velocity through the remainder of the flight to $\sim 4 \mathrm{~m} \mathrm{sec}^{-1}$ by controlling a valve at balloon apex. The gondola was separated from the balloon and deployed on a parachute at $1218 \mathrm{CDT}$, at an altitude of $20.0 \mathrm{~km}$.

Balloon descent performance is critical to the success of the mission since valid $\mathrm{OH}$ measurements are in general acquired only during the descent phase of the flight. Balloon performance in this flight was exceptional. The $\mathrm{OH}$ instrument performed nearly flawlessly throughout the mission, operating with improved stability in comparison with the 1987 flight. These improvements were the result of detailed thermal insulation and mechanical decoupling of various elements on the laser optical spar. The average uv power achieved in flight was $50 \%$ greater than the 1987 flight.

During the descent the instrument was operated in the OH detection mode $\sim 80 \%$ of the time. The overlap between the laser line and the $\mathrm{OH}$ absorption line was optimized five times. The method of overlap optimization and $\mathrm{OH}$ line identification is illustrated by the series of scans shown in Figure 1. These scans served as a check for nominal system operation while the gondola was floating at peak altitude.

Panels $A$ and $B$ of Figure 1 show two $O H$ fluorescence spectra produced by scanning the dye laser wavelength and monitoring, respectively, the $309 \mathrm{~nm}$ detector signal and the $\mathrm{OH}$ reference cell signal. An identical fluorescence spectrum is observed in both cases. Panel $\mathrm{C}$ shows the optimization of the laser overlap with the $Q_{1} 2$ line with a peak-finding algorithm that locates the wavelength a.t which the peak OH fluorescence count rate occurs from the reference cell. This wavelength represents the $\mathrm{OH}$
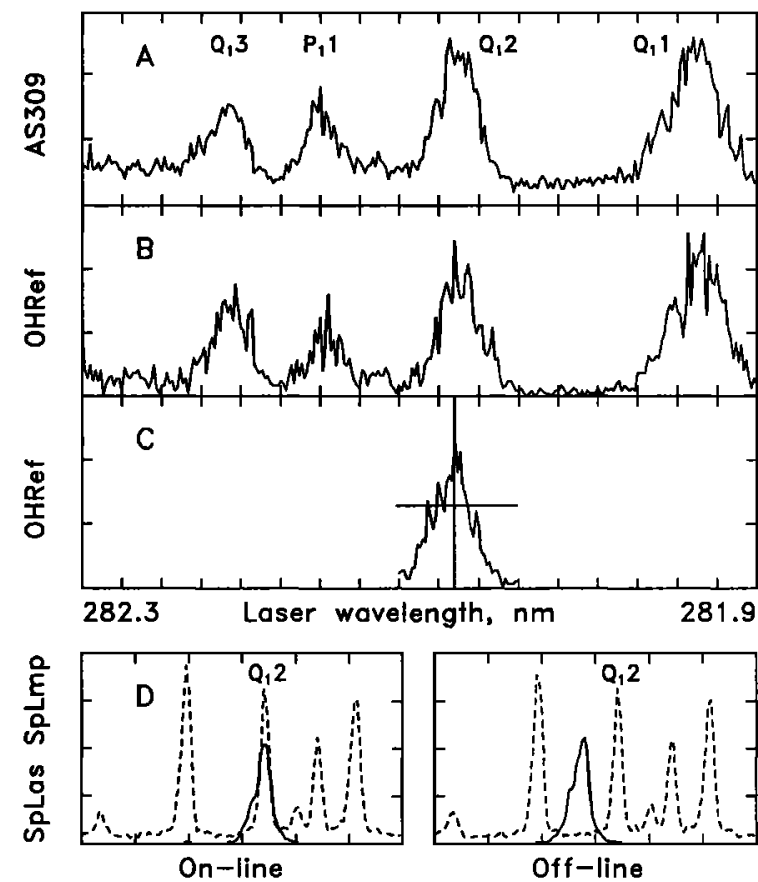

Fig. 1. Composite of five consecutive scans performed at float altitude. A) $309 \mathrm{~nm}$ detector count rate vs. wavelength; B) $\mathrm{OH}$ reference cell vs. wavelength; () $\mathrm{OH}$ reference cell vs. wavelength with computer peak finding algorithm; D) Resonant and non-resonant overlay of the laser (solid) and $O H$ lamp (dashed) outputs. 
on-line laser wavelength. Panel D shows the scanning spectrometer spectra for the on-line $\left(Q_{1} 2\right)$ and the operator selected off-line positions. The identity of the selected $\mathrm{OH}$ absorption feature is clearly established.

The magnitude of the signal shown in panel A of Figure 1 corresponds to an $\mathrm{OH}$ number density of $5.0 \times 10^{7}$ molec $\mathrm{cm}^{-3}$. This result does not represent an ambient $\mathrm{OH}$ measurement. During these scans the gondola was stationary and the pod fan was turned off. The pod fan is an axially mounted impeller at the exit of the flow pod that is used to generate a known flow velocity through the sampling pod independent of the gondola vertical velocity. Thus the detection volume contains stagnant air enriched in water vapor and other contaminates outgassing from the flow tube wall. An elevated $\mathrm{OH}$ signal is produced by the reaction of $O^{1}(D)$, formed by laser photolysis of ambient ozone, with water vapor. The $\mathrm{OH}$ fluorescence was observed to dramatically decrease, by a factor of 5 , upon turning the pod fan on and sweeping out the detection volume with clean stratosphere air.

The presence of laser induced $\mathrm{OH}$ is a potentionally serious problem with any $\mathrm{OH}$ detection scheme that employs a uv light source. In normal operatjons the air sample is unperturbed by the presence of the gondola, as confirmed by the thermistors which measure the temperature of the air flowing through the pod. Under these conditions an estimate of the upper limit on the amount of laser-induced $\mathrm{OH}$ produced by this system is $1.0 \times 10^{5}$ molec $\mathrm{cm}^{-3}$. A more thorough discussion of this effect will be presented in a future paper.

The detector count rates observed during the descent at various altitudes are given in Table 1 . The $\mathrm{OH}$ altitude profile measured in this flight is shown as the crosses in Figure 2. The enclosed region represents nur 1987 results. The solid line is a 2-D model calculation [Ko et al., 1985] as reported in SA. The number of individual $\mathrm{OH}$ measurements making up each point, going from high to low altitude, are: $1,5,5,5,8,9,10,10,10,10,10$ and 20 . The total averaging time for each point may be estimated given that a single $\mathrm{OH}$ measurement requires 20 seconds to record the on and off resonant signals. The data are binned as required to achieve the measurement precision shown. The horizontal error bars are $\pm 1 \sigma$ limits, the standard deviation of the mean value, except in the first point $(36.6 \mathrm{~km})$ where the precision is estimated based on photon counting statistics. The vertical error bars represent the altitude interval the measurements have been averaged over. The total measurement error (not shown) includes the estimated error in the absolute accuracy of $\pm 35 \%$ orginating from uncertainty in the calibration and the fluorescence efficiency. Data were taken down to 21.7 $\mathrm{km}$, but there was no detectable $\mathrm{OH}$ below $23 \mathrm{~km}$. An upper limit ( $\pm 1 \sigma$ precision) in this interval is $0.5 \mathrm{ppt}$.

There is no measurement reported in the 36.5 to $35 \mathrm{~km}$ interval because during this time the pod fan recieved a spurious off command and shut down. The fan off condition was not recognized for a few minutes after which it was commanded back on without furthur incident. During this interval the flow velocity through the pod slowed

TABLE 1. Average count rates (cts $\sec ^{-1}$ ) observed by the adjustable gate $309 \mathrm{~nm}$ detector at various altitudes.

\begin{tabular}{cccccccc}
\hline$Z$ & $E$ & $S$ & $S$ & $S$ & $S$ & $S$ & $S$ \\
$k m$ & $m W$ & On & Off & Solar & Chb & Bgd & OH \\
\hline 36.7 & 13.2 & 270 & 106 & 83 & 23 & 6.5 & 164 \\
33.4 & 12.0 & 203 & 113 & 87 & 21 & 9.3 & 91 \\
29.8 & 12.4 & 180 & 139 & 102 & 21 & 17 & 41 \\
25.6 & 12.1 & 137 & 129 & 70 & 21 & 34 & 8.2 \\
22.3 & 10.1 & 139 & 139 & 75 & 17 & 47 & 0.3 \\
\hline
\end{tabular}

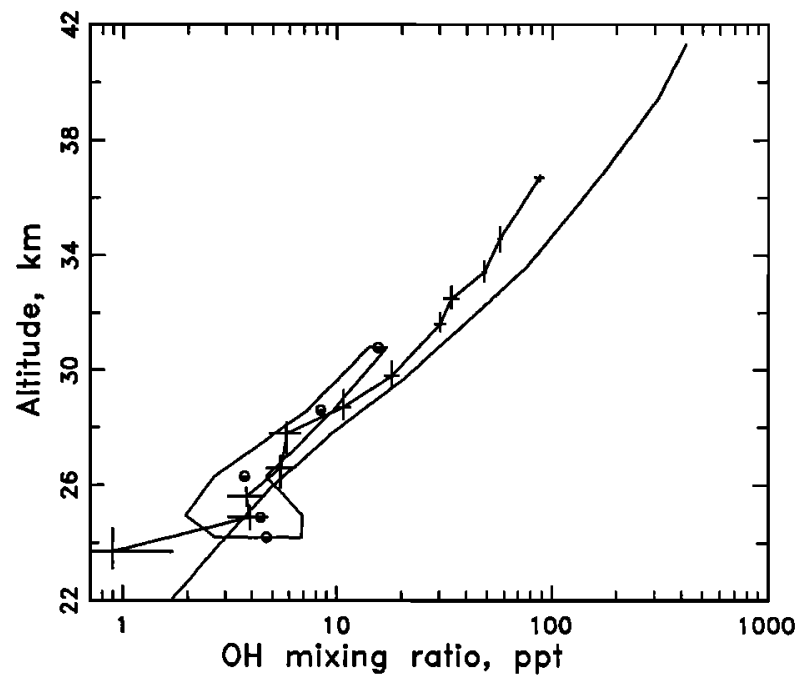

Fig. 2. $\mathrm{OH}$ mixing ratio vs, altitude. The crosses represent the 1988 results. The enclosed region represents the 1987 results, [Stimpfle and Anderson, 1988]. The solid line is a model calculation by [Ko et al., 1985] as reported in SA.

significantly. The core air flow temperature in the pod rose above the ambient air temperature by 5 to $10 \mathrm{~K}$ indicating the incursion of boundary layer air into the core of the flow. The $\mathrm{OH}$ data, which are reduced by 20 to $50 \%$ compared to the measurements directly before and after this event, are discarded due to instrument contamination. The temperature record for the remainder of the flight shows well-behaved flow through the detection chamber and no other data have been rejected.

As shown in Figure 2, our present results are in gond agreement with our 1987 results except at the altitude around $30 \mathrm{~km}$ where the 1987 results are lower by $\sim 40$ $\%$. The significance of this difference cannot be reliably quantified. From a statistical view point it clearly may be a result of instrumental variance between the two years. However it may be the result of natural variability of OII. The relative precisions of the two profiles is sufficiently high that a difference of this magnitude is resolvable. There is little experimental evidence to guide our appreriation for what variability one should expect or what is the source of the variability. An analysis of winter, midlatitude LIMS satellite observations of $\mathrm{NO}_{2}$ and $\mathrm{HNO}_{3}$ [Pyle and Zavody, 1988] concludes that $\mathrm{OH}$ can vary on the order of $\pm 20 \%$ due to fluctuations that are resolvable by satellite measurements. We do know from our simultaneous $\mathrm{O}_{3}$ and $\mathrm{H}_{2} \mathrm{O}$ measurements on both flights that $\mathrm{O}_{3}$ or $\mathrm{H}_{2} \mathrm{O}$ variability is not responsible.

An obvious method of differentiating between the effects of instrument variance and ambient $\mathrm{OH}$ variance is to include simultaneous detection of species in addition to $\mathrm{O}_{3}$ and $\mathrm{H}_{2} \mathrm{O}$ that control the density of $\mathrm{OH}$. Factors that give rise to $\mathrm{OH}$ variance observed from year to year or that observed during a single descent profile should be observable as fluctuations in other species photochemically linked to $\mathrm{OH}$. We expect to obtain nearly simultaneous $\mathrm{HO}_{2}$ measurements with the $\mathrm{OH}$ measurements in our next flight by injecting $\mathrm{NO}$ into the flow stream at the entrance to the detection pod. The $\mathrm{HO}_{2}+\mathrm{NO} \rightarrow \mathrm{OH}$ $+\mathrm{NO}_{2}$ reaction can be used to convert ambient $\mathrm{HO}_{2}$ to $\mathrm{OH}$. A measurement of the ratio of $\mathrm{OH}$ to $\mathrm{HO}_{2}$ will provide a challenging test of $\mathrm{HO}_{X}$ photochemistry as well as provide collaborative evidence concerning the natural variability of $\mathrm{OH}$.

In Figure 3 our present results are compared with the measurements of Carli and Park [1988], Carli et al. [1989], 
Heaps and McGee [1985] and Anderson [1976], with the latter two measurements as they were reported in SA. In SA the results of Heaps and McGee [1985] and Anderson [1976] were modified by a reevaluation of the fluorescence efficiency used in the original data analysis to remove a bias due to the use of different quenching data. The new rate constants adopted for $\mathrm{V}-\mathrm{V}$ transfer in this paper do not alter the reevaluation. The corrected Anderson [1976] measurements are unaffected since they do not involve pumping the $A, V=1$ state of $O H$. The corrected results of Heaps and McGee [1985] are subject to a change of $3 \%$, an insignificant amount, since they observe both $(1,1)$ and $(0,0)$ band fluorescence and the net effect on the total fluorescence efficiency into both bands is nearly zero.

In Figure 3 the data of Carli and Park [1988], Carli et al. [1989], Heaps and McGee [1985], SA and our 1988 results form a reasonably consistent set of independent measurements employing different techniques and strategies. The agreement is good considering the difficulty of measuring $\mathrm{OH}$ in the stratosphere. The Anderson [1976] measurements are markedly higher. The comparison with the other $\mathrm{OH}$ observations suggests that these measurements may be in error however there is no systematic error known to be responsible and we do not know how variable stratospheric $\mathrm{OH}$ may have been over the time interval between measurements.

Two additional calculations are shown in Figure 3 for comparison. The photochemical model calculation of McElroy and Salawitch [1989] is constrained by May, 1985 ATMOS measurements and is in good agreement with the OH measurements. The steady state calculation of Pyle and Zavody [1988] is based upon mid-winter, 1979 LIMS measurements of $\mathrm{NO}_{2}$ and $\mathrm{HNO}_{3}$.

The data shown in Figure 3 have not been scaled to correct for different solar zenith angles (SZA) characteristic of each data set. Although the observed $\mathrm{OH}$ column abundance [Burnett et al., 1988] provides a measurement of SZA variations averaged over all regions of the atmosphere, models predict a significant altitude-dependent SZA variation in the stratosphere. For example the predicted [OH] SZA dependence at $24 \mathrm{~km}$ is 2 to 3 times greater than that at $36 \mathrm{~km}$ (J. Rodriguez, private communication, 1989). In general, however, the estimated

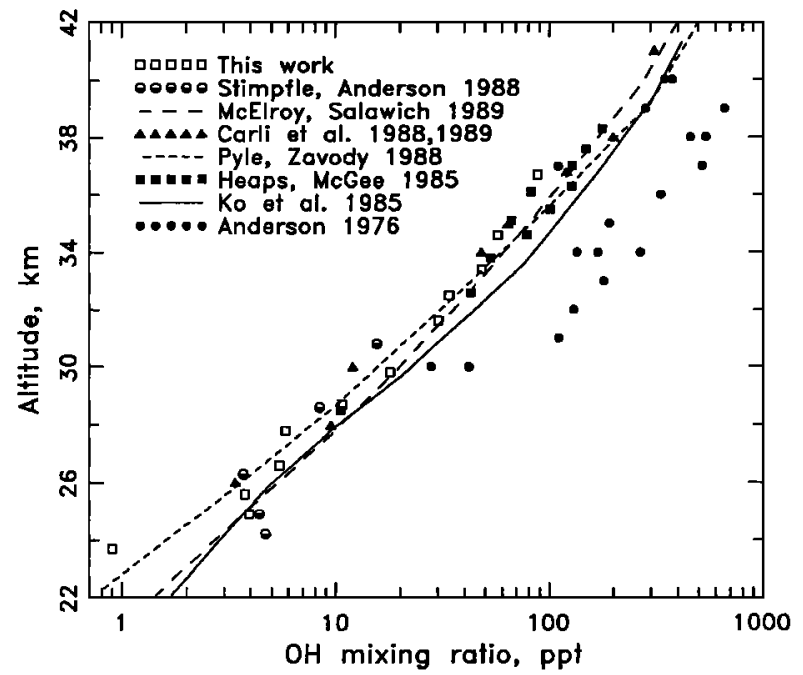

Fig. 3. OH mixing ratio vs. altitude. Composite of $\mathrm{OH}$ measurements by Stimpfle and Anderson [1988], Carli and Park [1988] and [1989], Heaps and McGee [1985], Anderson $[1976]$, and this work, and calculations by McElroy and Salawitch [1989], Ko et al. [1985], and Pyle and Zavody [1988]. corrections are less than the uncertainty of the measurements and the preliminary conclusions drawn here are not affected.

Our 1988 results have the highest internal precision and altitude resolution of in-situ $\mathrm{OH}$ measurements to date. The divergence of this data set with the models above $~$ $34 \mathrm{~km}$ is an interesting result. The reproducibility of this effect in future flights will address whether this result is due to variability or is a consistent finding. Simultaneous $\mathrm{HO}_{2}$ measurements will provide new information on the number density of this important radical.

Acknowledgements. We are indebted to J. Demusz, N. Allen, M. Mueller, N. Hazen, B. Heroux, E. Weinstock and the Atmospheric Research Group staff. The NSBF staff in Palestine, TX provided excellent support. Funds for this research were provided by NASA contract NASW 3960 .

\section{References}

Anderson, J. G., The absolute concentration of $\mathrm{OH}\left(\mathrm{X}^{2} \mathrm{II}\right)$ in the earth's stratosphere, Geophys. Res. Lett., 3, 165-168, 1976.

Burnett,C. R., K. R. Minschwaner, and E. B. Burnett, Vertical column measurements of atmospheric hydroxyl from $26 \mathrm{~N}, 40 \mathrm{~N}$, and $65 \mathrm{~N}, J$. Geophys. Res., g3, 5241-5253, 1988.

Burris, J., J. J. Butler, T. J. McGee and W. S. Heaps, Collisional deactivation rates for $\mathrm{A}^{2} \Sigma^{+}\left(v_{-}-1\right)$ state of OH, Chem. Phys., 124, 251-258, 1988.

Carli, B., M. Carlotti, B. Dinelli, F. Mencaraglia, and J. Park, The mixing ratio of the stratospheric hydroxyl radical from far infrared emission measurements, $J$. Geophys. Res., 94, 11049-11058, 1989.

Carli, B. and J. H. Park, Simultaneous measurement of minor stratospheric constituents with emission farinfrared spectroscopy, J. Geophys. Res., 93, 3851$3865,1988$.

Copeland, R. A., M. L. Wise, and D. R. Crosley, Vibrational energy transfer and quenching of $\mathrm{OH}\left(\mathrm{A}^{2} \Sigma^{+}\right.$, v'=1), J. Phys. Chem., 92, 5710-5715, 1988.

Ko, M. K. W., K. K. Tung, D. K. Weisenstein, and N. D. Sze, A zonal mean model of stratospheric tracer transport in isentropic coordinates: Numerical simulations for nitrous oxide and nitric acid, J. Geophys. Res., 90, 2313-2329, 1985.

Heaps, W. S. and T. J. McGee, Progress in stratospheric hydroxyl measurement by balloon-borne LIDAR, $J$. Geophys. Res., 90, 7913-7921, 1985.

McElroy, M. B. and R. J. Salawitch, Changing composition of the global stratosphere, Science, $243,763-770$, 1989.

Pyle, J. A. and A. M. Zavody, Radical variability determined from LIMS and SAMS satellite data, $J$. Atmos. Chem., 6, 201-220, 1988.

Stimpfle, R. M., and J. G. Anderson, In-situ detection of $\mathrm{OH}$ in the lower stratosphere with a balloon borne high repetion rate laser system, Geophys. Res. Lett., $15,1503-1506,1988$.

Weinstock, E. W., C. M. Schiller, and J. G. Anderson, In situ stratospheric ozone measurements by long path UV absorpion: Developments and interpretation, $J$. Geophys. Res., 91, 5237-5248, 1986.

J. Anderson, L. Lapson, R. Stimpfle and P. Wennberg, Harvard University, ESL, 40 Oxford St., Cambridge, MA 02138.

(Received: September 19, 1989;

revised: October 25, 1989; accepted: October 26, 1989) 